\title{
Evolution online: using a virtual learning environment to develop active learning in undergraduates
}

\author{
Lindell Bromham ${ }^{1}$ and Paolo Oprandi ${ }^{2}$ \\ ${ }^{1}$ Centre for the Study of Evolution, University of Sussex, UK, and ${ }^{2}$ School of Life Sciences, \\ University of Sussex, UK
}

\begin{abstract}
We show how an interactive website can help first-year undergraduates acquire independent study skills, and provide a user-friendly way of approaching challenging material in introductory level evolution and ecology. Students embraced the opportunity to undertake self-assessment tasks online, which allowed them to gauge their understanding and prepare for formal assessments.

Keywords: eLearning; Virtual learning environment; Self-assessment; Undergraduate
\end{abstract}

\section{Introduction}

There is no single definition of elearning. At its broadest, it is the use of any electronic technology to facilitate student learning, such as wikis (Lamb, 2004), mobile technologies ( $N$ aismith et al, 2004) and gaming (Kirriemuir and M cFarlane, 2004). H owever, when higher education institutions refer to the adoption of eLearning, they are generally referring to making existing course content available online. Typically, this involves asynchronous activities - students access material in their own time and do not interact with teachers or other students while doing so.

A primary motivation for the adoption of eL earning in higher education is to save money, particularly for large, introductory-level courses (H arley et al, 2004; M urphy, 2003). For research-based institutions, where academic staff must balance research and teaching activities, freeing staff time can be a strong motivation for adopting eL earning strategies. In addition, many university administrations are keen to appear to be using cutting edge technology and fear that failure to adopt elearning will suggest the university is 'falling behind', regardless of the measurable costs or benefits of elearning adoption.

The rush to implement eL earning has perhaps found full expression in the failure of Britain's ambitious online university UKeU, which gained only 900 of its target 5,600 students and was officially wound up in 2004, four years (and $f 50$ million) after it was launched. The failure of UKeU has been blamed on its development being technology-led rather than being centred on pedagogical goals and ideals (Education and Skills Committee, 2005).

A doption of eL earning in higher education typically begins with an administrative decision to back a specific Virtual Learning Envirnment (VLE) platform. Teachers are then encouraged to use the platform, usually without a fundamental change to course structure. The V LE is then used as an electronic version of some aspects of the existing course - for example, using the internet as a repository for lecture handouts. This makes the V LE a convenient resource, but does not fundamentally alter methods of teaching and learning (M urphy 2003). This kind of online availability of teaching materials can act as a 'safety net' for students, allowing missed classes to be repeated, or providing an alternative mode of learning for students with disabilities or illnesses (H arley et al, 2004). But given the cost of developing an online component to a university course in terms of both money and time, simply providing a back-up for face-to-face classes will in many cases not provide sufficient incentive for developing eLearning in higher education.

eL earning should only be adopted where it will substantially add to student experience (or significantly reduce costs, in terms of staff time or other resources, without inhibiting student experience). To achieve this, eLearning should not simply replace or duplicate existing course material, but act in combination with other teaching methods through a strategy of 'blended learning'. A $n$ examination of the benefits of different teaching delivery methods can lead to a combination of online and face-to-face teaching methods, in order to get the best of all possible worlds. An added benefit of this approach is that it lends itself to a diversity of learning styles, and allows students to benefit from a multi-faceted education (Carman, 2002; M urphy, 2003; Young, 2002).

In particular, eLearning tools have the potential to encourage student-directed learning. U nlike a large face-to-face class, online activities generally allow students to undertake tasks at their own pace, in a time and place that suits them. M oreover, interactive elearning tools provide the means for students to "be in control of their learning experience and should have the capability to modify and abstract their personal learning 
path"(D agger et al, 2004). H owever, one of the greatest challenges of a blended learning approach is to generate student engagement outside traditional face-to-face classes: there is a tendency for students to attend classes, but see the online components as optional (U niversity of N orth Texas, 2005).

\section{An interactive website for an introductory evolution course}

The aim of this project was to develop an internet-based resource to address several problems in teaching an introductory-level biology course. 'D iversity of Life' is a core first-year biology course at the U niversity of Sussex, covering topics in macroevolution (patterns and processes of the history of life) and macroecology (patterns and processes in the distribution of biodiversity). M ajor episodes from the history of life - such as the Cambrian explosion of animal life and the extinction of the dinosaurs - are used to illustrate macro-evolutionary patterns such as adaptive radiation and mass extinction. Global patterns of biodiversity, such as diversity gradients and hotspots, are examined in the light of evolutionary mechanisms, as well as ecosystem stability and function. This course attracts a diverse undergraduate recruitment of 90-150 students from a wide range of degree programmes. The primary teaching mode is through two lectures per week, plus four one-hour tutorials in classes of four to seven students. Formal assessment is through two short multiple-choice tests, an essay and a written exam.

Students come to the Diversity of Life course with a wide variety of backgrounds and interests. Some have studied biology through secondary school, others have never studied biology before. Some students are keenly interested in biology and see evolution and ecology as core subjects, but many others are taking the course because it is a compulsory component of their degree, and they may not be motivated to learn the subject beyond what is required for progression in their course. Entry-level undergraduates often have poor independent study skills, and require a great deal of direction to develop appropriate study habits. Furthermore, they may be uncomfortable with learning subjects, such as macroevolution and macroecology, that are largely based on a critical examination of hypotheses rather than on learning a catalogue of facts. The goal of this project was to develop an interactive online resource that would encourage active learning in evolution and ecology, through the provision of regular opportunities for self-directed study and self-assessment.

Student feedback shows that the Diversity of Life course is very popular, with a median score of five-out-of-five for interest and clarity. Yet while the overall response to the course was very positive, student feedback pointed to a number of key areas for improvement, particularly textbooks and online resources. There is no suitable textbook for the course, simply because no book currently available includes all the topics covered in this course at a level appropriate to entry-level undergraduates. In previous years, this need was met through the course handbook, occasional handouts and online material. But although feedback indicated that some students found the online material very helpful, many students considered it non-essential to the course. The majority of the students accessed the website only once or twice, whereas it was designed to be accessed every week to provide reinforcement and extension of the concepts covered in each lecture.

M ore generally, a common problem faced by first-year stu- dents is that they do not have a clear understanding of what is expected of them as independent scholars. $M$ any do not have strong independent study skills, nor do they have a clear idea of what their teachers expect of them in formal assessment - for example, it is becoming increasingly difficult to explain the concepts of plagiarism and "putting an idea in your own words" for a generation of students accustomed to finding information on the internet and pasting it into assignments. This leads to the frequent complaint from academics that undergraduates expect to be spoon-fed information to regurgitate for formal assessments. Furthermore, it can be difficult to persuade students to think critically about ideas presented and develop their own opinions about hypotheses in evolution and ecology (e.g. competing explanations for the latitudinal diversity gradients). W hile some students are excited by presentation of unanswered questions in lectures (e.g. did the Cambrian really explode?), many feel lost and frustrated when given both sides of a debate, and wish to be told only what is known with certainty.

\section{Methods}

We used the free open-source virtual learning environment M oodle. The open source ethos, where all users may contribute and improve the product in response to need and experience, is compatible with knowledge-sharing principles of academia. It also has the advantage of being constantly updated in response to user need. M oodle is browser-based, so is accessible to all users with an internet connection, with any type of computer. M oodle.org offers free support, however use of M oodle is most effective when there is the skill available inhouse to support and develop the platform. Alternatively, there are a variety of services available that will install or host M oodle for fees well below the licensing fees of commercial alternatives. We developed a Moodle platform, called LifeScilnteractive, that was integrated into the campus IT system, allowing students to use the same log-in they use for email and library access.

We included several broad categories of information on LifeScilnteractive: essential course information, lecture support, self-assessment questions, and a discussion forum. In order to blend the online material with the face-to-face classes, neither provided all the required information or materials, so a successful student must use both. For example, some essential information was provided only on the website (such as essay titles and support material), while not all material presented in face-to-face lectures was covered online.

For each of 15 key lectures of the course, we provided online support in one of two different formats. For five lectures, we provided a downloadable Powerpoint file containing all of the slides presented by the lecturer. The Powerpoint files allow students to review all of the material covered in the lecture, but they are not 'blended learning' because the online material simply reiterates the face-to-face class, so students could easily choose one or the other. For 10 lectures of the course, we provided a walk-through 'lesson' comprising approximately 10 onscreen pages, each of which had between one sentence and three paragraphs of text, with a continue button to take the reader to the next page. This format encourages students to read the text online at the time of access, rather than downloading and storing the information.

The subheadings for the walk-through lectures notes were consistent across all such lessons; for example, an Ideas and 
Information section that reiterated key points from the lectures, particularly complex ideas that students may not have been able to adequately cover in their notes. In order to encourage students to develop an active, critical approach to lecture material, each lesson included open questions, under the headings Points to $\mathrm{C}$ onsider and $\mathrm{Q}$ uestions to Ponder, to encourage students to think beyond the material presented in the lecture and to form their own opinions about the ideas presented. This section also served to remind students that macroevolution and macroecology are subjects best considered as ongoing debates, not simply a collection of established facts. Because first year students often have little idea where to start searching for relevant information, each lesson contained a list of useful resources (e.g. textbook references, library resources, internet links) to provide a platform for developing independent study habits.

The last page of the lesson linked to two multiple-choice self-assessment questions (SAQs) related to that lecture, usually taken from previous years' test papers. Students got immediate feedback on whether they had selected the right answer, and this contributed to a cumulative SAQ score for the term. The SAQ s were not compulsory and did not contribute to formal assessment. To promote regular self-study habits, the lecture notes and SAQs had a limited shelflife: they appeared on the day of the relevant lecture, then disappeared after three weeks to encourage regular access rather than leaving revision to the night before a test.

\section{Evaluation}

We used four kinds of data to evaluate website usage and effectiveness:

i) A printed questionnaire, with questions requiring either scored response or written comments, was given to students after they had finished their end-of-term exam, a strategy that ensures a $>95 \%$ response rate. $M$ any of the questions were identical in 2004 and 2005 to allow direct comparison before and after the introduction of the virtual learning environment (VLE).

ii) To test whether students who received regular reminders about eL earning exercises in face-to-face classes were more likely to undertake online tasks, the tutors of half of the tutorial groups actively encouraged web access and checked if students had completed the SAQ s. Formal assessment scores and website access rates were compared using an unpaired t-test (experimental group $\mathrm{N}=$ 45 , control group $\mathrm{N}=48$ ).

iii) We monitored VLE usage through detailed website access logs which recorded student name, time and date of access, and pages viewed.

iv) We tested for a correlation between individual participation in elearning activities and performance in the formal assessment items for the course, using general linear models to examine the relationship between access rates, SAQ completion rates, SAQ scores, scores in multiple choice tests, and overall score for the course.

\section{Results}

We demonstrated a strong increase in web access rates between 2004, when online material was presented in a noninteractive, text-based format, and 2005, when the online material was an interactive V LE (see Figure 1). In 2005, all students accessed the website at least once and $96 \%$ of students accessed the site several times. The percentage of students who used the website every week (the target rate) tripled to nearly $30 \%$. Increase in website access did not simply reflect the fact that some information was now disseminated exclusively online: all parts of the V LE were accessed by at least $20 \%$ of the class, with up to $70 \%$ of students viewing information that was also available in the printed handbook. Similarly, the increase in access was not due to a change in the information available: the text of the online lecture support was similar in both 2004 and 2005, only the mode of presentation changed. We also showed that, although students frequently requested downloadable lecture slides, these 'non-blended' lecture support files had much lower access rates than the 'interactive' lecture support. O n average, over two thirds of the class completed the interactive online lessons, but less than a third of the class downloaded the Powerpoint slides (this is unlikely to be a reflection of a lack of interest in the subject matter, since these lectures also received high scores for interest).

Student perceptions of the usefulness of the website material increased when the online material was presented as a VLE: the percentage of students giving the website the target score for usefulness increased from $16 \%$ to $26 \%$. So the same information was given a higher score for usefulness when presented in an interactive format that promoted regular access to course materials. There was no negative feedback about the lack of a textbook or poor preparation for formal assessments in 2005, as there had been in 2004 when the online material was accessed at a much lower rate. These observations show that by successfully embedding the V LE into the structure of the course, students were actively encouraged to study in their own time, and this contributed positively to their ability to complete the course.

Comments from the student questionnaires were generally very positive, for example:

- It was good and provided another resource for information. I found it helpful at times when I needed to understand something I didn't quite get in lecture.

- V. easy to understand. The notes pointed at the main parts which helped structure revision and the self-assesment q's helped know what needed more work.

- The webpage was clear and contained useful information on lectures and tutorials and the SAQ s were good because they allowed you to assess your progress as you went along in the course

Figure 1. Students were given a written questionnaire that asked them to score their response to several questions: each question has a target score of 5 .

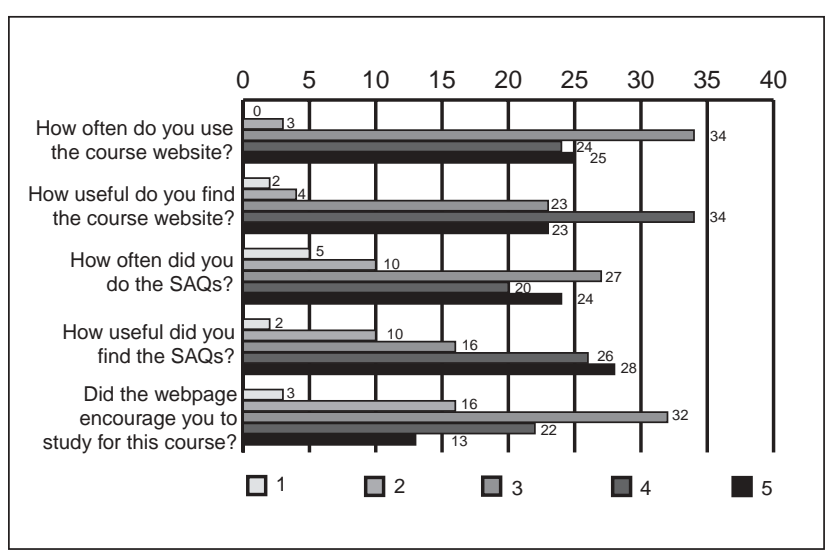


(a) How often did you access the website?

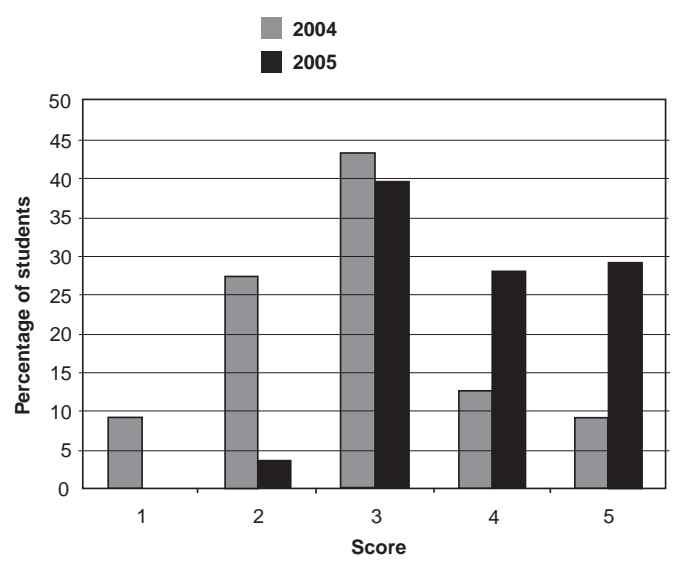

(b) How useful was the website?

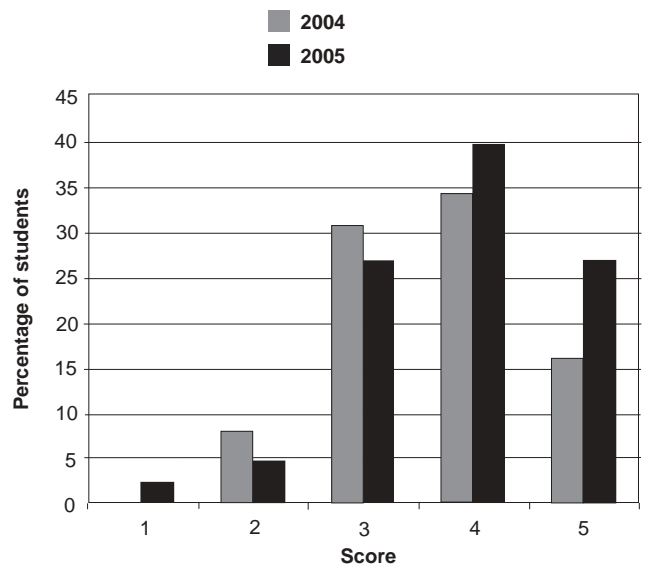

Figure 2. Comparisons of 2004 and 2005 questionnaire scores. The scale for question (a) was: 1 = never, 2 = once, 3 = several times, 4 = often, $5=$ every week. The scale for question (b) was from $1=$ not useful to $5=$ very useful.

Face-to-face encouragement to undertake web-based activities did not increase web usage: the experimental and control groups did not differ significantly in their web access rates $(t=0.002, p=0.98)$ nor in the number of SAQ $s$ completed $(t=-0.481, p=0.632)$. However, web access rates for online lessons and SAQ s tended to peak on the days of subsequent lectures, throughout the three weeks that they were available online. This suggests that attending face-to-face classes stimulates online access. D ata from web logs suggest that it was not

Figure 3. A significant correlation between average test score for the two multiple-choice tests against the number of SAQs completed (for statistical tests see text).

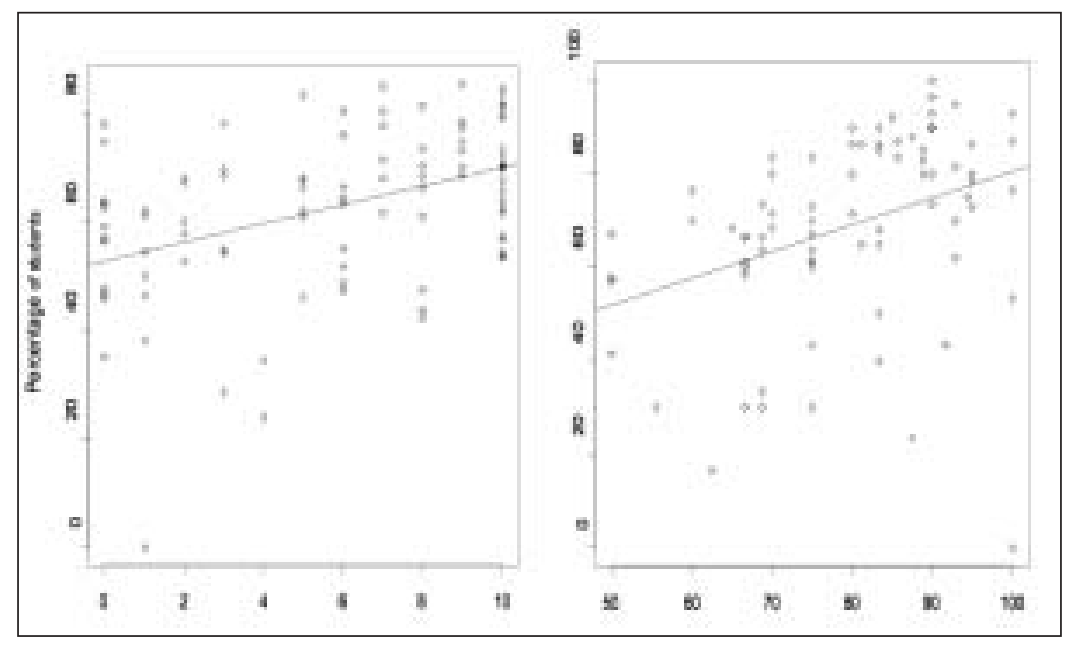

necessary to use a limited shelf-life to encourage prompt access, because the majority of the class accessed online material in the week following the lecture, with little evidence of a peak in access just before the lessons were taken offline.

There was no apparent correlation between number of webpages accessed and student performance in the course ( lope $=0.136, p=0.62$, d.f. $=89$ ). H owever, there was a significant positive correlation between participation in online selfassessment activities and performance in formal assessment tasks. The number of SAQ s completed was significantly positively correlated with test scores on both of the multiplechoice tests ( $d f=88$ : First test: slope $=1.405, p=0.001$; Second test slope $=2.116, p=0.00$ ), and with the overall course score ( lope $=1.709, p=0.000$ : see Figure 3a). There are two possible explanations of this result: undertaking the SAQs improved student performance on tests, or good students who perform well in tests are also those who seize the opportunity for self-assessment. Either way, it corroborates the widespread support amongst the student body for SAQ S as an effective study tool. Furthermore, performance in SAQ $s$ was linked to performance in formal assessments. Figure $3 \mathrm{~b}$ shows that, of the students that completed one or more SAQ S, the percentage of correct SAQ s was significantly positively associated with the average score on the multiple-choice tests ( lope $=0.569, p=0.001, d f=76$ ). Students can therefore regard the SAQ s as an accurate indicator of their future performance in formal assessment.

\section{Discussion}

This project succeeded in its aim of encouraging self-study by increasing student use of online lecture support material. Student rating of the usefulness of the website increased when we moved from a text-based format to an interactive VLE. Although all online lessons were non-compulsory, an average of two-thirds of the class completed each online lesson, the majority doing so within a week of the relevant lecture. Students made use of different media for accessing information about the course, using the webpages even when the information was available in printed format. The SAQ $s$ were the most successful part of the website, demonstrating that students will embrace the opportunity for regular self-assessment. O ver half the class reported that they did the SAQ s "often" or "every week", and SAQ completion rates were linked to performance in formal assessment. O nline multiple-choice questions provided students with continuous feedback on comprehension and performance, a service that could not easily be replicated in a non-electronic medium.

Students were noticeably more self-sufficient when the course support material was presented as an interactive VLE, and staff found they had to spend much less time fielding questions about assessment items. Unlike the previous year, when the same supporting information was available but was used less often by students, there were no negative comments about the lack of a core text, or poor preparation for formal assessments. Most students who accessed the SAQ s did so within a week or so of the relevant class, indicating that they were studying regularly during the course and not leaving the SAQ exercises until just before the 
formal assessments

Students also reported that the online lecture notes provided a useful resource for revisiting the topics covered in the lecture, so students could take the initiative to cover again any areas they had not understood. The essay 'hints' appear to have had a very positive effect on active learning, as students could gain enough information to start researching their essay independently, in contrast to previous years when many felt lost and not sure where to start. This provided tangible benefits in terms of staff time saved.

Several large-scale trials of introductory level university courses have suggested that the introduction of elearning tools does not improve student performance, particularly when face-to-face lessons are simply transferred to an electronic medium without adaptation (Cornford and Pollock, 2003; $\mathrm{H}$ arley et al, 2004; M urphy, 2003). But replacing face-to-face classes is not the only way for el earning to substantially save resources. We have shown that a 'blended learning' programme, using a VLE to supplement face-to-face classes, can bring clear benefits to entry-level biology students by providing them with an alternative way of learning and assessing their progress. We believe that this approach saves staff time by producing more confident students who are better able to direct their own study.

O ur VLE trial has suggested that eLearning tools can improve student learning without substantial cost to resources, apart from the staff time taken in the initial development phase. Asynchronous online activities allow students to approach challenging subjects of macroevolution and macroecology in their own time at their own pace. Self-assessment tasks provide encouragement to regular self-study. M ost importantly, it provides students with a non-threatening introduction to independent study and critical assessment of hypotheses. Simple elearning tools, such as walk-through lessons and multiple choice self-assessment questions, can be implemented through the free M oodleV LE software without the need for expensive licences or campus-wide administrative decisions.

\section{Conclusions}

The 'virtual university', a campus without walls, was a term first coined to describe the potential for life-long learning promised by urbanisation, where citizens would have easy access to knowledge and skills (Tiffin and Rajasingham, 2003). Similarly, the push to adopt eLearning can be at least partly attributed to widening access to higher education, because it is frequently seen as a solution to the strain on resources brought about by decreasing staff-to-student ratios in undergraduate courses. Adoption of eLearning will not revolutionise higher education simply by providing another portal for information access (though it may fulfil that task as well). The real university experience is from interaction with teachers and students in an atmosphere of learning. Electronic resources may be developed to facilitate this process, but they will not do so automatically. However, eL earning tools can offer very real advantages in terms of teaching delivery and student access.

This project has shown that an internet resource can offer a real enhancement to a university course by providing something not easily delivered through face-to-face classes: the opportunity for regular and relevant self-assessment, directed by the teacher and aligned with the curriculum, but actively driven by the student's own desire to study and learn.

\section{Acknowledgments}

We thank M arcel Cardillo for statistics advice and the teachers and students of the Diversity of Life course 2005 who trialled the VLE and gave us such helpful feedback.

\section{References}

Carman J M (2002) Blended learning design: five key ingredients. Product D evelopment KnowledgeN et

Cornford J, Pollock N (2003) Putting the university online: information technology and organizational change. Open University Press, Buckingham

Dagger D, Wade V, Conlan O (2004) A Framework for D eveloping A daptive Personalized eL earning E-L earn 2004: World C onference on $\mathrm{E}$-Learning in Corporate, $\mathrm{G}$ overnment, $\mathrm{H}$ ealthcare and $\mathrm{H}$ igher Education, Washington, D.C

Education and Skills Committee (2005) UK eUniversity Third Report of Session 2004-05. H ouse of Commons, London

Harley D, Henke J, M aher M (2004) Rethinking Space and Time: The Role of Internet Technology in a Large Lecture Course. Innovate: J ournal of 0 nline Education 1

Kirriemuir J, M cFarlane A (2004) Literature Review in G ames and Learning. N esta FutureL ab

Lamb B (2004) Taking a Walk on the Wiki Side. Syllabus. A pril

M urphy P (2003) The hybrid strategy: Blending face-to-face with virtual instruction to improve large section courses. Teaching, Learning, and Technology Center, University of California Regents.

Naismith L, Lonsdale P, Vavoula G, Sharples M (2004) Literature Review in M obile Technologies and Learning. N esta FutureL ab

Tiffin J and Rajasingham L (2003) The global virtual university. RoutledgeFalmer, London

University of N orth Texas (2005) Blended learning project

Young J R (2002) 'Hybrid' Teaching Seeks to End the Divide Between Traditional and $\mathrm{O}$ nline Instruction. $\mathrm{C}$ hronicle of $\mathrm{H}$ igher Education

Lindell Bromham (corresponding author) is CO-D irector of the Centre for the Study of Evolution at the University of Sussex, and is now at the Centre for Macroevolution and Macroecology at the Australian National University, C anberra, ACT 0200 Australia. Web: www.tempoandmodecom, email: lindell.bromham@anu.edu.au, Fax +61-2-6125 5573, Phone +61-2- 6125 9545. Paolo 0 prandi is an educational technologist at the School of Life Sciences, University of Sussex, Falmer BN19Q G UK. Email: paolo@sussex.ac.uk, Fax: +44-(0)1273 678057, Fax: +44-(0)1273678433. 